\title{
AÇÃO SOCIOEDUCATIVA SOBRE RECICLAGEM E PRESERVAÇÃO AMBIENTAL EM UMA COOPERATIVA DE CATADORES NA CIDADE DE LORENA/SP
}

\author{
Janaína Aparecida da Silva \\ Universidade de São Paulo \\ janaina.as@alunos.eel.usp.br
}

Camila Cezar Grillo

Universidade de São Paulo camila.grillo@gmail.com

Clodoaldo Saron Universidade de São Paulo saron@usp.br

\section{Resumo}

Este trabalho teve como objetivo realizar uma análise sobre o ambiente de trabalho em uma cooperativa de reciclagem de materiais na cidade de Lorena (São Paulo) e realizar intervenções socioeducativas no sentido valorizar a autoestima, disseminar o conhecimento ambiental sobre a problemática do lixo e motivar os cooperados, conscientizando-os sobre a importância que eles têm no contexto social. A metodologia utilizada consistiu do mapeamento dos trabalhos, desafios e problemas enfrentados no cotidiano da cooperativa de forma semanal, e realização de aulas, vídeos e atividades em grupo. A educação ambiental como transmissor de conhecimento proporcionou mudanças nos envolvidos, como a conscientização sobre a importância de seus atos para a sociedade e ao meio ambiente, bem como permitiu compreender que os desafios e dificuldades em empreendimentos que lidam com a reciclagem possibilitam vivências únicas tanto no campo profissional como pessoal. Além disso, observou-se que os principais desafios no ambiente da cooperativa são referentes às relações humanas.

Palavras-chave: Educação Ambiental. Cooperativa. Reciclagem.

\section{SOCIO-EDUCATIONAL ACTION ON RECYCLING AND ENVIRONMENTAL PRESERVATION IN A COLLECTORS COOPERATIVE IN LORENA/SP, BRAZIL}

\begin{abstract}
This study aimed to perform an analysis on the working medium in a material recycling cooperative in the Lorena city (São Paulo - Brazil) as well as to perform socio-educational interventions for the purpose of enhance self-esteem, disseminate environmental knowledge about the garbage problem and motivate workers, making them aware about their importance in the social context. Methodology was based in a mapping on work, challenges and problems of the cooperative everyday . Meetings with presentation of videos and group activities have been made weekly. The use of environmental education as knowledge transmitter has caused positive changes for those involved such as awareness on the importance of their actions for society and environment as well as it allowed understand that challenges and difficult lead to the notable experiences both in the professional field as a personal. Moreover, it is observed that the main challenges in the cooperative are related to the human relations.

Keywords: Environmental Education. Cooperative. Recycling.

\section{ACCIÓN SOCIO-EDUCATIVA EN EL RECICLAJE Y PRESERVACIÓN DEL MEDIO AMBIENTE EN UNA COOPERATIVA DE COLECTORES EN LORENA/SP, BRASIL}

\section{Resumen}

Este estudio tuvo como objetivo realizar un análisis sobre el medio de trabajo en una cooperativa de reciclado de materiales en la ciudad Lorena (Brasil), así como para llevar a cabo intervenciones socioeducativas con el propósito de mejorar la autoestima, difundir el conocimiento del medio ambiente sobre el problema de la basura y motivar los trabajadores, haciéndoles tomar conciencia acerca de su importancia en el contexto social. En la metodología se ha realizado un mapeo de trabajo, los retos y problemas de la vida cotidiana cooperativa y que se han realizado reuniones semanales con presentación de videos y actividades de grupo. El uso de la educación ambiental como transmisor de conocimiento ha provocado cambios positivos para los involucrados tales como la conciencia sobre la importancia de sus acciones para la sociedad y el medio ambiente, así como que permitió entender que los desafíos y plomo difícil a las experiencias notables tanto en el campo profesional como personal. Por otra parte, se observa que los principales retos de la cooperativa están relacionadas con las relaciones humanas.

Palavras clave: Educación ambiental. Coperativa. Reciclaje. 
Ação socioeducativa sobre reciclagem e preservação ambiental em uma cooperativa de catadores na cidade de Lorena/SP

\section{INTRODUÇÃO}

\section{POLÍTICA NACIONAL DE RESÍDUOS SÓLIDOS}

A Política Nacional de Resíduos Sólidos incorpora as cooperativas de reciclagem de materiais ou cooperativas de catadores como entidades de importância fundamental no gerenciamento de resíduos sólidos, sendo estas responsáveis pelos altos índices de reciclagem nacional. Em 2010, quando a Política Nacional de Resíduos Sólidos entrou em vigor, no Brasil haviam 443 municípios com programa de coleta seletiva de resíduos. Quatro anos depois, em 2014, o número de municípios aumentou para 927. Na Figura 1 é apresentada uma distribuição percentual das regiões do País onde estes municípios estão localizados.

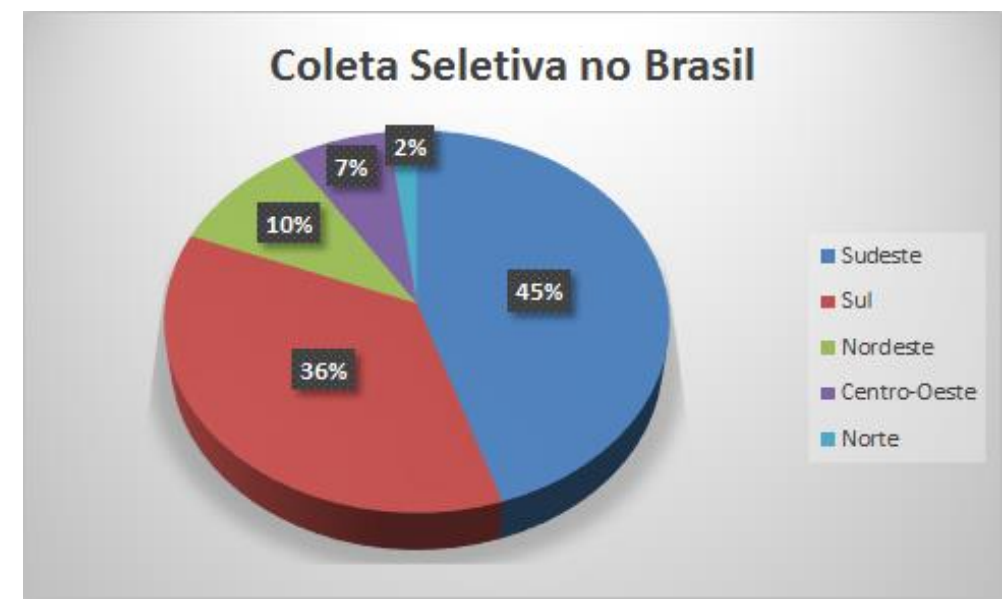

Figura 1-Localização regional dos municípios com coleta seletiva no Brasil. Fonte: CEMPRE, 2014.

De acordo com a Constituição Federal, o poder público municipal tem a responsabilidade da limpeza urbana, coleta e destinação final do lixo. Com esta nova lei, as prefeituras possuem princípios e diretrizes com o potencial de mudar o panorama do lixo no Brasil.

A coleta e o transporte dos resíduos sólidos domiciliares produzidos em imóveis residenciais, em estabelecimentos públicos e no pequeno comércio são, em geral, efetuados pelo município encarregado da limpeza urbana. Grandes geradores de resíduos sólidos, definidos de acordo com lei municipal, devem contratar empresas particulares, cadastradas e autorizadas pela prefeitura, para a realização da coleta e transporte. Pode-se, então, conceituar como coleta domiciliar comum ou regular o recolhimento dos resíduos sólidos urbanos produzidos nas edificações residenciais, públicas e comerciais, desde que não sejam considerados grandes geradoras (MANSOR, M. T. C. et al, 2010) 
Ação socioeducativa sobre reciclagem e preservação ambiental em uma cooperativa de catadores na cidade de Lorena/SP

A entrega voluntária é realizada pelos cidadãos em postos específicos, chamados de Postos de Entrega Voluntária (PEVs) localizados em áreas pré-determinadas. A ampla divulgação da importância da participação de cada cidadão, bem como os dias de coleta, é fundamental para o sucesso da coleta seletiva. Os materiais recolhidos pela coleta seletiva e aqueles entregues nos PEVs são encaminhados às centrais de triagem. As unidades de triagem podem contemplar desde uma mesa simples até equipamentos mais complexos como esteiras, balanças, elevadores. Os materiais não recicláveis são denominados rejeitos, e devem ser encaminhados da central de triagem para aterros sanitários.

A coleta seletiva é a coleta de resíduos sólidos que foram previamente separados conforme sua constituição ou composição. O processo envolve coleta e triagem, tendo a participação dos catadores individuais, catadores que pertencem às cooperativas, sucateiros de pequeno porte, médio ou grande porte (LEI 12.305, 2010).

\subsection{Educação Ambiental}

Dentro desta perspectiva, o projeto visa incentivar e conscientizar a responsabilidade realizada pelos cooperados com o uso da educação ambiental. A Lei Federal n. 9.795 institui educação ambiental como:

\footnotetext{
“entende-se por Educação Ambiental os processos por meio dos quais o indivíduo e a coletividade constroem valores sociais, conhecimentos, habilidades, atitudes e competências voltadas para a conservação do meio ambiente, bem de uso comum do povo, essencial à sadia qualidade de vida e sua sustentabilidade" (POLÍTICA NACIONAL DE EDUCAÇÃO AMBIENTAL, 1999).
}

A educação ambiental permite uma proposta pedagógica centrada na conscientização, mudança de comportamento, desenvolvimento de competências, capacidade de avaliação e participação dos cooperados. Nesse sentido, segundo Jacobi (2003), cabe destacar que a educação ambiental assume cada vez mais uma função transformadora, na qual a co-responsabilização dos indivíduos torna-se um objetivo essencial para promover um novo tipo de desenvolvimento - o desenvolvimento sustentável. Segundo Hendges (2010), a Educação Ambiental permite a construção de valores sociais, habilidades, e atitudes que compreendem os processos de construção de valores sociais e conservação do meio ambiente. Isto é importante para a vida de cada um e sua sustentabilidade. Portanto, esta educação deve estar presente em todos os níveis de ensino, de forma articulada, contínua e permanente para todos. 
Ação socioeducativa sobre reciclagem e preservação ambiental em uma cooperativa de catadores na cidade de Lorena/SP

A educação ambiental na área dos resíduos sólidos e a obtenção das informações sobre as possibilidades e dificuldades do setor, ações propostas e quais possam ser incentivadas são de suma importância. Também é extremamente relevante ter clareza do que se pode realizar no contexto atual dos municípios brasileiros (EIGENHEER, 2003).

\subsection{Cooperativa de Catadores da cidade de Lorena}

A Cooperativa de Catadores da cidade de Lorena-SP (COOCAL) é uma entidade com organização simples, cujas funções dos cooperados são definidas de acordo com o objeto ou natureza das atividades desenvolvidas por eles, constituídas nos termos da Lei 5764/71, como define a Política Nacional de Cooperativismo e a legislação em vigor da área. As cooperativas são regidas pelo Estatuto Social e pelo Regimento Interno. O Regimento Interno corresponde às necessidades e prioridades definidas pelos cooperados, e pode variar de um grupo de cooperados para outro (MNCR, 2015).

Atualmente, a COOCAL conta com a participação de oito mulheres e quatro homens. A COOCAL está vinculada à prefeitura da cidade e desenvolve parcerias com empresas, universidades e escolas que permitem a presença de alunos da rede publica para visitação e projetos para continua melhoria. Entretanto, a cooperativa carece ainda de apoio para o treinamento e capacitação de cooperados ingressantes e de aperfeiçoamento do conhecimento e valorização das atividades desenvolvidas pelos cooperados com maior tempo de serviço, focando na importância que estes têm para a sociedade e ao meio ambiente. Este projeto é parte de uma parceria entre a Escola de Engenharia de Lorena e a COOCAL.

O presente estudo teve como objetivo a observação do ambiente da COOCAL, avaliação do comportamento e verificação das principais dificuldades enfrentadas pelos cooperados, abertura de um canal de diálogo com os cooperados e a promoção e divulgação do conhecimento sobre o meio ambiente e a problemática do lixo, por meio de aulas expositivas e atividades em grupo, no sentido de melhorar a autoestima e a motivação entre os cooperados.

\section{MATERIAIS E MÉTODOS}

Os materiais utilizados foram papeis cartolinas, canetas, materiais recicláveis e projetor multimídia para as aulas expositivas.

O método utilizado consistiu de visitas semanais à COOCAL, com início no ano de 2014. A primeira etapa do trabalho foi o acompanhamento das atividades desenvolvidas na cooperativa, seguida da avaliação sobre a sua realidade. Simultaneamente foi estabelecido um canal de diálogo 
Ação socioeducativa sobre reciclagem e preservação ambiental em uma cooperativa de catadores na cidade de Lorena/SP

com os cooperados, buscando uma confiança mutua e o esclarecimento sobre os motivos para a realização do trabalho. $\mathrm{Na}$ sequência, foi elaborado, em comum acordo, um calendário para a realização de encontros semanais para aulas socioeducativas e sobre educação ambiental para os cooperados. As aulas buscaram valorizar a discussão sobre os desafios encontrados no ambiente de trabalho, troca de experiências e maneiras para melhorar as atividades e o bem-estar na cooperativa. A Figura 2 apresenta um fluxograma que ilustra as etapas de desenvolvimento do trabalho.

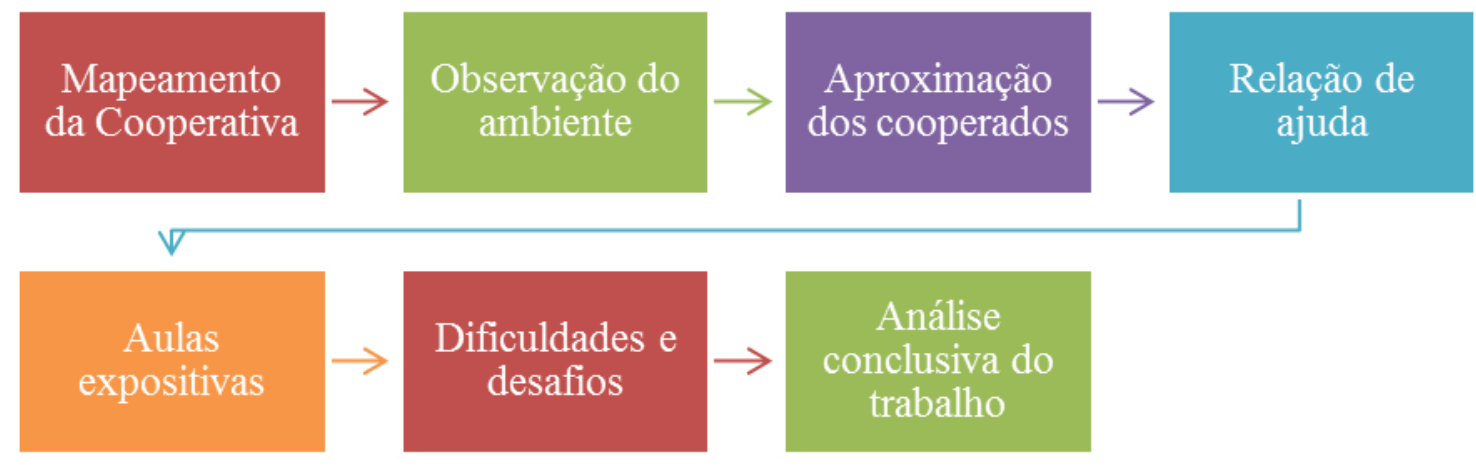

Figura 2: Fluxograma das etapas realizadas. Fonte: Própria do autor.

\section{RESULTADOS}

\subsection{Mapeamento da Cooperativa}

A cooperativa COOCAL localiza-se na rua Lorena, número 20, bairro Santo Antônio, Lorena - SP, em um bairro periférico, próximo à estrada que faz ligação entre as cidades de Lorena e Guaratinguetá. Os cooperados são em maioria mulheres, com faixa etária entre 30 a 60 anos, enquanto que para cooperados homens não há padrão de idade. A maioria apresenta escolaridade baixa e vulnerabilidade econômica e social. O número de trabalhadores no local é flutuante e a alta rotatividade se deve em maior parte à presença masculina por falta da adaptação das atividades realizadas pelas mulheres. Os cargos existentes de liderança são presidente e tesouraria, demais são cooperados ou funcionários da prefeitura. $\mathrm{Na}$ última visita realizada a cooperativa contava com 12 cooperados, dos quais 8 mulheres e 4 homens. Observou-se que existe ampla diversidade de materiais que são processados na cooperativa, cerca de 50 materiais, majoritariamente materiais poliméricos, que são separados de acordo com seu valor agregado. A dinâmica de trabalho entre os cooperados ocorre a partir do tipo de maquinário que deverá ser 
Ação socioeducativa sobre reciclagem e preservação ambiental em uma cooperativa de catadores na cidade de Lorena/SP

utilizado para a separação de cada material, compondo os procedimentos executados no dia-a-dia. Os materiais são obtidos por meio da coleta em 8 empresas da região e 5 entidades públicas, entre elas escolas municipais de Lorena, Universidade de São Paulo, Instituto de pesquisa INPE, um ponto de entrega voluntária (PEV) no supermercado Pão de Açúcar e o complexo hospitalar Santa Casa de Lorena.

\subsection{Observação do ambiente}

As cooperadas mulheres passam parte do tempo em trabalho repetitivo e nos intervalos desabafam entre si os seus problemas familiares e de saúde. O horário do trabalho ocorre das $8 \mathrm{~h} 30$ às $11 \mathrm{~h} 30$ e das $13 \mathrm{~h} 30$ às $17 \mathrm{~h} 00$, com intervalos de 15 min pela manhã e pela tarde. Observou-se que não há fidelidade com o horário de trabalho e de retorno após intervalos por parte de alguns cooperados. Muitos cooperados não têm a responsabilidade de ir diariamente ao trabalho devido à liberdade de escolha, motivos de saúde ou falta de visão financeira e motivacional para as atividades realizadas.

O local de trabalho não possui padrão organizacional adequado. Entretanto, os cooperados conseguem se organizar, com dificuldade, para o processamento dos materiais. Basicamente as atividades são distribuídas entre separação dos materiais, prensagem dos materiais separados em fardos, direção do caminhão que faz a coleta e coleta propriamente dita dos materiais nos diversos pontos da cidade.

A prefeitura da cidade auxilia em diversas ações realizadas como a disponibilidade em tempo integral de um profissional com grande conhecimento e experiência em reciclagem. $\mathrm{O}$ ambiente é aberto e não tem controle das pessoas que entram e saem do local sem registro.

\subsection{Aproximação com os cooperados}

O primeiro contato iniciou-se pelo funcionário da prefeitura que informou o desejo pela realização do projeto em visitas semanais para o acompanhamento das atividades desenvolvidas pelos cooperados. Ocorreu posteriormente a informação das atividades para a presidente anterior responsável pela cooperativa. A análise do campo de trabalho iniciou-se de forma distante através da janela de uma sala superior e nesta observação a primeira impressão foi dada pela outra líder da tesouraria que se aproximou de forma desconfiada, quando foi estabelecido um diálogo sobre a necessidade do acompanhamento do cotidiano da cooperativa. Essa observação à distância resultou em uma desconfiança dos demais cooperados devido à existência de pessoas 
Ação socioeducativa sobre reciclagem e preservação ambiental em uma cooperativa de catadores na cidade de Lorena/SP

desconhecidas, mesmo com a comunicação da presidência e do funcionário da prefeitura. $\mathrm{O}$ próximo passo foi à aproximação no local de trabalho de cada cooperado como a esteira e a prensa para a explicação clara se existia o interesse e a necessidade do projeto na visão delas. Para ter esse resultado, a confiança delas foi conquistada após 6 meses de conversas. Essa barreira inicial se deve ao fato do desconhecimento sobre a intenção do projeto, e também pelo fato da existência de um projeto anterior que não teve resultados satisfatórios, de acordo com relatos dos próprios cooperados. Esse resultado anterior insatisfatório, segundo elas, foi devido à complexibilidade da forma apresentada de soluções que necessitavam de um longo acompanhamento pós-projeto. Com aprovação dos cooperados para a realização do projeto, foi entregue a cada cooperado o planejamento das atividades na forma de um cronograma.

\subsection{Relação de ajuda}

A relação interpessoal neste trabalho permitiu a ação de ajudar na necessidade que o outro apresenta e ser ajudado para aprender as atividades desenvolvidas pelos cooperados, assim como o entendimento da dinâmica na Cooperativa. Previamente, foi necessário conhecer o nome, gostos, realidades, o trabalho, a dificuldade e a história de cada indivíduo. Nos laços criados, observou-se uma confiança, liberdade de expressão sobre suas dificuldades no trabalho, dificuldades de entendimentos e gostos para realizar as atividades referentes à proposta do projeto. Mediante essa relação, o cronograma foi modificado, visto que esse tempo para iniciar as atividades foram cruciais mesmo sendo depois de seis meses de interação. Nesta relação, teve-se o risco de não realizar o projeto com todo o conteúdo programado e ocorrer o desinteresse por parte dos cooperados. Os participantes foram divididos com relação às mulheres que estavam presentes e participativas em todas as aulas e os homens que em sua maioria não participavam; isso ocorreu pela decisão em deixar aberta a cada um a participação ou interrupção das atividades do projeto.

Nesta etapa, foi reconhecido e exposto pelas cooperadas que a maior dificuldade está na relação humana durante as atividades do dia-a-dia. Com isto, pode-se explicar a rotatividade dos cooperados que foi observado e nas atividades desenvolvidas. Esta interação permitiu o entendimento sobre as atividades da cooperativa e a contribuição do projeto com o ensino.

\subsection{Aulas expositivas}


Ação socioeducativa sobre reciclagem e preservação ambiental em uma cooperativa de catadores na cidade de Lorena/SP

Uma vez conhecida à dinâmica da cooperativa e as necessidades dos cooperados, foram ministradas aulas expositivas de cunho socioambiental, a fim de demonstrar a importância do trabalho executado por eles, tanto para a sociedade como para o meio ambiente, visando assim estimulá-los e principalmente valorizá-los pelas suas atividades realizadas diariamente.

Após o estabelecimento do cronograma de atividades, discutido e decidido com o consenso dos cooperados, deu-se o ponto de partida por meio de uma dinâmica que consistia em 3 etapas: a primeira na confecção da árvore dos sonhos, momento em que se discutiu os objetivos a serem alcançados; em seguida o muro das lamentações, na qual discutiu-se os desafios a serem enfrentados para alcançar os objetivos estipulados, e por fim o caminho das realizações, em que foi traçado o plano de ação para chegar ao idealizado na árvore dos sonhos. Concomitante a isso, foi apresentado aos cooperados o conceito teórico de cooperativismo, estimulando-os na reflexão sobre a situação da cooperativa. Para reforçar a ideia de cooperativismo, foram aplicados atividades e vídeos que valorizavam e demonstravam o trabalho em equipe como ferramenta para alcançar os objetivos em comum.

Visando dimensionar o papel dos cooperados na mitigação da problemática do lixo, colocando-os como protagonistas, procederam-se aulas de cunho ambiental. Os conteúdos foram apresentados de modo simples, por meio de vídeos e aulas expositivas. Os temas abordados foram conceitos teóricos sobre ecossistema e desequilíbrio ecológico, meio ambiente, o ser humano e o lixo, reciclagem e sustentabilidade. Ao decorrer das apresentações a abertura para o debate sobre os temas foi de início aceito, propiciando maior interação entre os cooperados.

\subsection{Desafios e dificuldades}

O desenvolvimento de relações de confiança foi algo imprescindível para a execução do trabalho e que demandou um tempo considerável para que os envolvidos no projeto tivessem o entendimento sobre o trabalho, participação significativa nas aulas, definição do dia e horário para os encontros, e atuação dos cooperados em muitas decisões como forma da apresentação das atividades. Observações positivas a respeito dos laços de confiança criados foram a cobrança por parte dos cooperados de quando haveria a mudança do dia de semana ou ausência devido ao calendário universitário, mesmo com aviso antecipado e o reconhecimento dos envolvidos no projeto. A integração dos cooperados resultou na decisão de algumas atividades não serem realizadas ou serem feitas de forma quinzenal devido à demanda de trabalho. 
Ação socioeducativa sobre reciclagem e preservação ambiental em uma cooperativa de catadores na cidade de Lorena/SP

Dificuldades foram observadas com relação à perseverança de todos os participantes nas atividades desenvolvidas, visto à falta de motivação pessoal para suas atividades, mesmo com as alterações para dinâmicas e filmes. A limitação apresentada pelas cooperadas nestas aulas estava mais na ajuda no trabalho do que a necessidade do equipamento, visto que há operações que exigem força física como carregamento e descarregamento nos caminhões, bags com vidros ou metais, a retirada da prensa do fardo de alumínio, papel e plásticos.

Entre as dificuldades em se ministrar as atividades foi à preocupação em preparar um material que despertasse interesse entre eles e estabelecesse uma linguagem de fácil compreensão. Apesar dos conceitos teóricos, foi dada a atenção em utilizar exemplos simples e próximos ao dia-a-dia dos cooperados.

\section{CONSIDERAÇÕES FINAIS}

A aplicação da educação ambiental, como forma de transmissão de conhecimento, proporciona uma mudança de realidade na vida dos envolvidos, gerando uma mudança de conscientização sobre a importância de seus atos para a sociedade e meio ambiente.

O estudo proporcionou experiências e ampliação dos conhecimentos na vivência de uma cooperativa para a construção das aulas e atividades com o auxílio direto dos cooperados.

Percebeu-se que as principais dificuldades apresentadas pela cooperativa são de natureza humana e não de cunho financeiro, ou seja, as relações interpessoais entre os cooperados eram precárias, a percepção de trabalho em equipe defasada e a visão de negócio pouco trabalhada.

\section{REFERÊNCIAS}

BRASIL. Lei 12.305 de 2 de agosto de 2010. Política nacional de resíduos sólidos. Presidência da República. Casa Civil. Subchefia para Assuntos Jurídicos. 2010. Disponível em: <http://www.planalto.gov.br/ccivil_03/_ato2007-2010/2010/lei/112305.htm>. Acesso em 29 de Set. 2016.

EIGENHEER, E. M. Coleta seletiva de lixo: experiências brasileiras, n. 4, Rio de Janeiro, 2003.

HENDGES, Antônio S. Educação e a política nacional de resíduos sólidos, Lei

12.305/2010. 18 Ago 2010.2 Disponível


Ação socioeducativa sobre reciclagem e preservação ambiental em uma cooperativa de catadores na cidade de Lorena/SP

< http://www.ecodebate.com.br/2010/08/18/educacao-e-a-politica-nacional-deresiduos-solidoslei-12-3052010-artigo-de-antonio-silvio-hendges/>. Acesso em 13 de Set de 2016.

JACOBI, P. Educação ambiental, cidadania e sustentabilidade. Caderno de Pesquisa, São Paulo, n.118, p. 189-205, 2003.

MANSOR, M. T. C.; CAMARÃO, T. C. R. C.; CAPELINI, M.; KOVACS, A.; FILET, M.; SANTOS, G. A.; SILVA, A. B. Cadernos de Educação Ambiental. Resíduo sólido, 2010, v. 6.

MNCR. Movimento nacional dos catadores de materiais recicláveis. Disponível em: < http://www.mncr.org.br/biblioteca/legislacao/leis-e-decretos-federais/lei-no-5-764-de-16-dedezembro-de-1971-lei-geral-do-cooperativismo/view?searchterm=cooperativa $>$. Acesso em 29 de Set de 2016.

REIGOTA, M. Desafios à educação ambiental escolar. Educação, meio ambiente e cidadania: reflexões e experiências. São Paulo, SMA/CEAM, p.43-50, 1998.

COMPROMISSO EMPRESARIAL PARA RECICLAGEM. Um relato de 20 anis de coleta. Disponível em: <http://cempre.org.br/cempre-informa/id/7/um-retrato-de-20-anos-da-coletaseletiva-no-pais> .Acesso em: 7 de Mai. 2015. 